\title{
REMODELING BISNIS PT SASAKURA INDONESIA DENGAN MENGGUNAKAN BUSINESS MODEL CANVAS (BMC)
}

\author{
Humam Mahmudi \\ Fakultas Ekonomi Universitas Negeri Jakarta \\ Email: humammahmudi2018@gmail.com \\ Mohammad Rizan \\ Fakultas Ekonomi, Universitas Negeri Jakarta \\ Budi Santoso \\ Fakultas Ekonomi, Universitas Negeri Jakarta
}

\begin{abstract}
ABSTRAK
Business Model Canvas bertujuan membantu perusahaan untuk mengenali apa yang menjadi value proposition perusahaan, serta bagaimana membangun dan menjalankan key activities dan key resources dalam menciptakan value proposition dan mendapatkan revenue streams, memahami bagaimana produk dan jasa yang ditawarkan perusahaan dapat dikomunikasikan dengan baik kepada konsumen. Data dari dokumen laporan dalam bentuk hard copy maupun soft copy yang ada di PT Sasakura Indonesia sekaligus sebagai perusahaan yang di teliti. Jenis data primer yaitu data yang berasal langsung dari sumber data yang dikumpulkan secara khusus dan berhubungan langsung dengan permasalahan yang di teliti dengan cara observasi, wawancara, Sedangkan jenis data sekunder diperoleh melalui kajian pustaka, review penelitian relevan sebelumnya, dokumen dan laporan rutin perusahaan. Hasilnya dapat diketahui posisi perusahaan berdasarkan review SWOT, yang menunjukkan bahwa perusahaan PT Sasakura Indonesia masih memiliki peluang cukup baik untuk merebut pasar atau konsumen, dimana strategi yang dapat digunakan yaitu kombinasi strategi Strength-Opportunity. Denggan begitu dapat dibuatkan remodelling business model canvas baru yang selaras dengan posisi SWOT dan strategi baru yang mendukung terlaksananya business model canvas baru yang dibuat.
\end{abstract}

Kata kunci: Desalinasi, SWOT, Remodelling, Business Model Canvas, PT Sasakura Indonesia 


\section{PENDAHULUAN}

Perkembangan bisnis industri pembuatan mesin desalinasi melalui teknologi MultiStage Flash (MSF) and Reheat Type (RH type) saat ini mulai merambah ke bidang perkapalan dengan mengunakan jenis teknologi fresh water generator. Industri ini digunakan untuk fresh water yang dihasilkan dari fresh water generator di atas kapal, air ini digunakan untuk minum, memasak, mencuci, dan bahkan menjalankan mesin penting lainnya yang menggunakan air tawar. Sedangkan untuk dijadikan sebagai media pendingin seperti pada kegiatan pembangkit listrik (PLTU, dan PLTGU) mengunakan teknologi Multi-Stage Flash and Reheat Type.

PT Sasakura Indonesia bergerak di bidang jasa, pabrikasi, pembuatan teknologi desalinasi Multi-Stage Flash (MSF) dan Reheat Type (RH type) dan juga membuat design plan land use untuk pembangkit tenaga listrik. Penyediaan tenaga listrik di Indonesia yang mengunakan pembangkit Listrik Tenaga Uap (PLTU) membutuhkan air tawar yang cukup besar. Air tawar akan digunakan sebagai bahan steam yang berguna untuk menggerakan mesin turbin sekaligus pencegah berbagai jens sifat korosit.

Selama beroperasi PT Sasakura Indonesia pernah mengalami situasi yang sangat berat dalam pendapatannya seperti penurunan keuntungan selama tahun 2016-2017. Penurunan project order, sehingga yang semula setahun dapat menghasilkan keuntungan perusahaan sebesar 3 milyar rupiah, namun pada saat itu perusahaan justru merugi sebesar 2,19 milyar rupiah. Kerugian ini sebagai dampak dari kondisi global dan kondisi ekonomi dalam negeri.

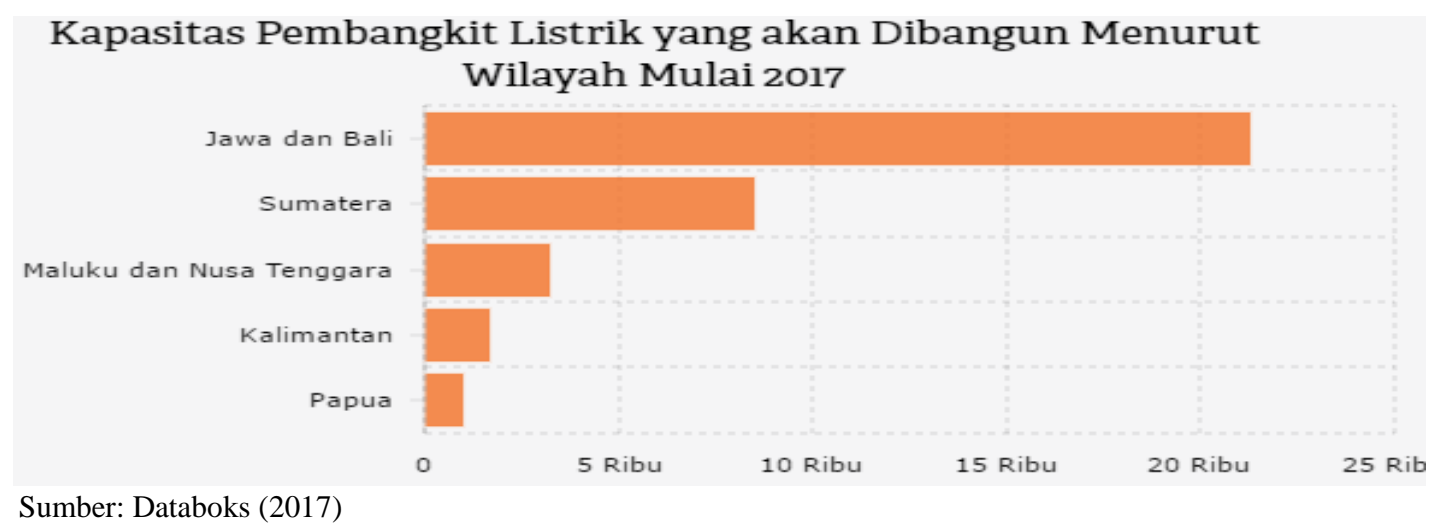

Gambar 1. Kapasitas pembangkit listrik yang akan dibangun di Indonesia

Permasalahan yang telah dihadapi oleh PT Sasakura Indonesia saat ini adalah masih terbatasnya permintaan (order) dari project owner atau penguna jasa dari dalam negeri, 
sehingga berdampak besar pada penurunan tingkat profit perusahaan. Dalam kondisi profit yang terus merosot, PT Sasakura Indonesia patut mengadakan perubahan. Sehingga dalam menghadapi permasalahan yang ada tersebut, PT Sasakura Indonesia perlu melakukan penyesuaian Bussines Model Canvas (BMC) yang baru.



Sumber: Financial report PT Ssakura Indonesia (2017)

Gambar 2. Merosotnya tingkat profit PT Sasakura Indonesia di 2013-2017.

Beberapa hasil penelitian sebelumnya menunjukkan hasil yang positif terhadap memperbaiki business model canvas bagi perusahaan yang sedang mengalami profit loss. Untuk itu penelitin ini bertujuan untuk memahami business model PT Sasakura Indonesia lama yang sedang dijalankan, posisi perusahaan berdasarkan review SWOT PT Sasakura Indonesia, dan uapya untuk membuat business model canvas baru yang sejalan dengan analisa SWOT yang baru pada PT Sasakura Indonesia.

\section{TELAAH PUSTAKA}

\section{Manajemen Strategi}

Menurut Porter (1993:13) strategi adalah tentang posisi bersaing, tentang perbedaan dirimu di mata customers, tentang nilai tambah dalam sejumlah kegiatan yang berbeda dengan apa yang dilakukan oleh pesaing. Sedangkan menurut Mintzberg \& Quin (1991:53), strategi adalah upaya pencarian cara yang disengaja lakukan untuk suatu rencana aksi untuk mengembangkan dan menyesuaikan persaingan. Hal ini seperti yang diungkapkan oleh Husseini dan Hutabarat (2006:10) dari berbagai pengertian dan 
definisi, secara umum dapat didefinisikan bahwa strategi adalah rencana tentang serangkaian manuver, yang mencakup seluruh element yang kasat mata maupun yang tidak kasat mata untuk menjamin keberhasilan mencapai tujuan. Dari ketiga pendapat di atas, maka strategi dapat diartikan sebagai suatu rencana yang disusun oleh manajemen puncak untuk mencapai tujuan yang diinginkan.

Strategi hampir selalu dimulai dari apa yang dapat terjadi dan bukan dimulai dari apa yang terjadi. Misalnya strategi itu mungkin mengarahkan organisasi itu ke arah pengurangan biaya, perbaikan kualitas, dan memperluas pasar. Terjadinya kecepatan inovasi pasar yang baru dan perubahan pola konsumen memerlukan kompetensi inti (core competencies). Perusahaan perlu mencari kompetensi bisnis yang dilakukannya.

\section{Analisis SWOT}

Menurut Rangkuti (2008:78), analis SWOT adalah indifikasi berbagai factor secara sistematis untuk merumuskan strategi perusahan. Analisis ini didasarkan pada logika yang dapat memaksimalkan kekuatan (sterngths) dan peluang (opportunities), namun secara bersamaan dapat meminimalkan kelemahan (weaknesses) dan ancaman (threats). Analisis SWOT menurut Kotler (2009:90) diartikan sebagai evaluasi terhadap keseluruhan kekuatan, kelemahan, peluang, dan ancaman. Analisis SWOT merupakan salah satu instrumen analisis lingkungan internal dan eksternal perusahaan yang dikenal luas. Sedangkan menurut Ferrel dan Harline (2005), fungsi dari Analisis SWOT adalah untuk mendapatkan informasi dari analisis situasi dan memisahkannya dalam pokok persoalan internal (kekuatan dan kelemahan) dan pokok persoalan eksternal (peluang dan ancaman). Analisis SWOT tersebut akan menjelaskan apakah informasi tersebut berindikasi sesuatu yang akan membantu perusahaan mencapai tujuannya atau memberikan indikasi bahwa terdapat rintangan yang harus dihadapi atau diminimalkan untuk memenuhi pemasukan yang diinginkan.

Tujuan dan strategi dibuat guna memanfaatkan kekuatan internal dan mengatasi kelemahan. Berikut ini merupakan penjelasan dari SWOT, yaitu :

1) Kekuatan (Strengths)

Kekuatan adalah sumber daya, keterampilan, atau keungulan-keungulan lain yang berhubungan dengan para pesaing perusahaan dan kebutuhan Kekuatan ini kompetisi khusus memberikan keunggulan kompetitif bagi perusahaan di pasar.

2) Kelemahan (Weakness) 
Kelemahan adalah keterbatasan atau kekurangan dalam sumber daya, keterampilan, dan kapabilitas yang secara efektif menghambat kinerja perusahaan. Keterbatasan tersebut dapat berupa fasilitas, sumber daya keuangan, manajemen dan keterampilan pemasaran dapat merupakan sumber dari kelemahan.

3) Peluang (Opportunities)

Peluang adalah situasi penting yang menguntungkan dalam lingkungan perusahaan. Kecendrungan-kecendrungan penting merupakan salah satu sumber peluang, seperti perubahan teknologi dan meningkatnya hubungan antara perusahaan dengan pembeli atau pemasok merupakan peluang bagi perusahaan.

4) Ancaman (Threats)

Ancaman adalah situasi penting yang tidak menguntungan dalam lingkungan perusahaan. Ancaman merupakan pengganggu utama bagi posisi sekarang atau yang diinginkan perusahaan. Adanya peraturan-peraturan pemerintah yang baru atau yang direvisi dapat merupakan ancaman bagi kesuksesan perusahaan.

\section{Matriks SWOT}

Beberapa literatur dari hasil penelitian sebelumnya banyak membahas mengenai SWOT sebelum melakukan membuat dan remodelling business model canvas. Menurut Rangkuti (2006:26), matriks SWOT dapat menggambarkan secara jelas bagaimana peluang dan ancaman eksternal yang dihadapi perusahaan dapat disesuaikan dengan kekuatan dan kelemahan yang dimilikinya. Matriks ini dapat menghasilkan empat pola kemungkinan altenatif strategis. Keempat pola tersebut sangat penting untuk dijadikan acuan dalam membangun strategi baru.

\begin{tabular}{|c|c|c|}
\hline IFAS & Kekuatan (Strengih) & Kelemahan (Weakness) \\
\hline Peluang (Opportunity) & $\begin{array}{l}\text { STRATEGI SO } \\
\text { Ciptakan strategi yang } \\
\text { menggumakan kekuatan } \\
\text { untuk melmanfaatkan } \\
\text { peluang }\end{array}$ & $\begin{array}{l}\text { STRATEGI WO } \\
\text { Ciptakan strategi yang } \\
\text { meminimalkan kelemahan } \\
\text { untuk memanfaatkan } \\
\text { peluang }\end{array}$ \\
\hline Ancaman (Threars) & $\begin{array}{l}\text { STRATEGI ST } \\
\text { Ciptakan strategi yang } \\
\text { menggunakan kekuatan } \\
\text { untuk mengatasi ancaman }\end{array}$ & $\begin{array}{l}\text { STRATEGI WT } \\
\text { Ciptakan strategi yang } \\
\text { meminimalkan kelemahan } \\
\text { dan menghindari ancaman }\end{array}$ \\
\hline
\end{tabular}

Sumber: Freddy Rangkuti (2006)

Gambar 3. Pola matriks strategi dari SWOT 
Berikut ini adalah keterangan dari matriks SWOT di atas :

1) Strategi SO (Strengths and Opportunity). Strategi ini dibuat berdasarkan jalan pikirann atau persepsi dari perusahaan, yaitu dengan memanfaatkan seluruh kekuatan untuk merebut dan memanfaatkan peluang sebesar-besarnya.

2) Strategi ST (Strengths and Threats).

Strategi dalam menggunakan kekuatan yang dimiliki perusahaan untuk mengatasi ancaman.

3) Strategi WO (Weakness and Opportunity).

Strategi ini diterapkan berdasarkan pemanfaatan peluang yang ada dengan cara meminimalkan kelemahan yang ada.

4) Strategi WT (Weakness and Threats).

Strategi ini berdasarkan kegiatan yang bersifat defensif dan berusaha meminimalkan kelemahan yang ada serta menghindari ancaman.

\section{Pendekatan kualitatif matriks SWOT}

Pendekatan kualitatif matriks SWOT sebagaimana dikembangkan oleh Kearns (dalam David, 2002:30) merupakan menampilkan delapan kotak, yaitu dua paling atas adalah kotak faktor eksternal (Peluang dan Tantangan), sedangkan dua kotak sebelah kiri adalah faktor internal (Kekuatan dan Kelamahan). Serta empat kotak lainnya tersebut merupakan kotak yang berisi isu-isu strategis yang muncul, hal ini sebagai hasil titik pertemuan antara faktor-faktor internal dan eksternal.

\begin{tabular}{c|c|c}
\hline EKSTERNAL & OPPORTUNITY & TREATHS \\
\hline INTERNAL & Comparative & Mobilization \\
\hline STRENGTH & Aduantage & \\
\hline WEAKNESS & Divestimeintlinvestment & Dainage Control
\end{tabular}

Sumber : Fred R. David. Manajemen Strategis (2002)

Gambar 4. Matriks SWOT Kearns

\section{Business Model Canvas (BMC)}

Untuk memahami definisi model bisnis, kajian model bisnis ini menggunakan terminologi model bisnis yang didefinisikan oleh beberapa akademisi. Giorgetti (dalam Duce dan Giorgetti, 1998:3) mengatakan model bisnis adalah model referensi yang merupakan sebuah dasar bagi sebuah sistem jenis (type) baru yang mempunyai keunggulan/kelebihan dibandingkan pendekatan sebelumnya. 
Osterwalder \& Pigneur (2012) mengatakan bahwa model bisnis dapat dijelaskan dengan sangat baik melalui sembilan balok bangun dasar yang memperlihatkan cara berfikir tentang bagaimana cara perusahaan menghasilkan uang, yang dinamakan dengan Business Model Canvas. Business Model Canvas juga membantu perusahaan untuk mengenali apa yang menjadi value proposition perusahaan, serta bagaimana membangun dan menjalankan key activities dan key resources dalam menciptakan value proposition dan mendapatkan revenue streams, memahami bagaimana produk dan jasa yang ditawarkan perusahaan dapat dikomunikasikan dengan baik kepada konsumen hingga sampai ketangan konsumen untuk dikonsumsi.

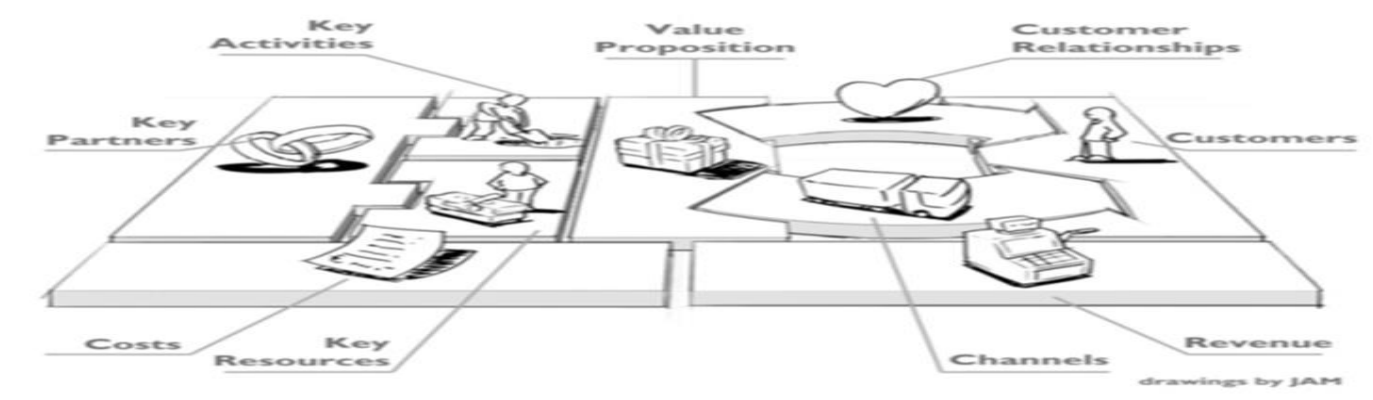

Sumber: Osterwalder dan Pigneur (2010)

Gambar 5. Sembilan Elemen Business Model Canvas (BMC)

\section{Customer Segments}

Menurut Mullin \& Walker (2010: 67), menyatakan bahwa segmentasi pasar adalah suatu proses membagi pasar menjadi kelompok customer yang berbeda berdasarkan kesamaan ciri dan kebutuhan yang akan mengarahkan mereka di dalam menanggapi suatu produk yang ditawarkan dan program pemasaran secara seragam.

\section{Value Proposition}

Menurut Osterwalder (2010:22-25), proporsisi nilai menggambarkan bagaimana customer dapat beralih dari satu perusahaan ke perusahaan lain melalui produk atau layanan yang ditawarkan oleh perusahaan berbeda dengan kompetitornya. Beberapa elemen yang dapat memberikan kontribusi di dalam menciptakan suatu nilai bagi customer antara lain newness, performance, customization, getting the job done, design, brand/status, price, cost reduction, risk reduction, accessabilty dan convenience/usability.

\section{Channels}

Menurut Laksana (2008:123), saluran distribusi adalah serangkaian organisasi yang terkait dalam semua kegiatan yang digunakan untuk menyalurkan produk dan status 
pemilikannya dari produsen ke konsumen. Pendapat lain dalam Daryanto (2011:90) mengemukakan bahwa saluran distribusi adalah saluran yang dipakai oleh produsen untuk menyalurkan barang hasil produksinya kepada konsumen, baik berpindahnya hak (penguasaan) hingga pemindahan barang maupun hanya pemindahan hak kepemilikannya.

\section{Customer Relationships}

Beberapa kategori hubungan dengan customer yang dapat diimplementasikan kepada setiap segmen customer yang di miliki perusahaan antara lain dalam bentuk personal assistance, dedicated assistance, self-service, automated services, communities dan co-creation. Hubungan dengan customer di bangun sesuai dengan customer segment, dikarenakan setiap setiap segmentasi memiliki yang berbeda. Dalam menjalin hubungan yang baik dengan customer dapat dilakukan dengan tiga cara yakni Customer Acquisition, Customer Retention, dan Upselling.

\section{Revenue Streams}

Hal ini akan menjelaskan mengenai kondisi keuangan/kas yang dihasilkan oleh perusahaan, dengan menyediakan produk dan jasa yang dihasilkan kepada segmen konsumen yang akan dicapainya. Seluruh biaya akan dikurangkan dari besarnya pendapatan untuk memperoleh penghasilan bersih (net profit) bagi perusahaan.

\section{Key Resources}

Dengan Key resources ini memungkinkan perusahaan untuk menciptakan dan menawarkan jasa layanan, memasuki pasar, menjaga hubungan dengan customer sesuai segmennya dan memperoleh pendapatan. Setiap bisnis model memiliki key resources yang sudah barang tentunya dapat mempunyai model yang berbeda-beda satu sama lain, namun key resources tetap terdiri dari faktor phsysical, intellectual, human dan financial. Hubungan dengan customer mengutamankan kemudahan bagi mereka.

\section{Key Activities}

Kegiatan utama perusahaan dibutuhkan untuk menciptakan dan menawarkan value proposition, memasuki pasar, memelihara hubungan dengan customer dan memperoleh pendapatan. Setiap bisnis model memiliki kegiatan utama yang berbeda sesuai dengan jenisnya dan dapat dikategorikan ke dalam bentuk production, problem solving dan platform or network yang mengandalkan kekuatan jaringan seperti software industry.

\section{Key Partnerships}


Menjelaskan jaringan pemasok dan rekanan yang di miliki perusahaan agar dapat menjalankan operasionalnya sesuai dengan bisnis model yang di buat. Jenis kerjasama dapat dikategorikan menjadi 4 jenis yang antara lain strategic alliances, coopetition, Joint Venture, buyer-supplier relationships.

\section{Cost Structure}

Ciri dari struktur biaya dapat dikelompokkan ke dalam beberapa unsur yang terdiri dari fixed cost, variable cost, economic of scale, dan economies of scope. Secara alamiah biaya harus diminimalkan pada setiap bisnis model akan tetapi suatu struktur biaya yang rendah belum tentu sesuai untuk semua jenis kegiatan usaha yang dilakukan, sehingga bisnis model dapat dikategorikan berdasarkan kepentingannya terhadap struktur biayanya ke dalam 2 (dua) bagian:

1) Cost-driven yaitu bisnis model yang fokus kepada meminimalkan biaya pada setiap kesempatan. Pendekatan ini bertujuan untuk menciptakan dan menjaga struktur biayanya agar tetap ramping, menggunakan low price value proposition, maximum automation dan extensive outsourcing.

2) Value-driven yaitu tidak terlalu memikirkan berapa besarnya biaya yang telah dikeluarkannya apabila perusahaan tersebut dapat menciptakan nilai layanan terbaik bagi customer. Menggunakan premium value proposition dan layanan prima bagi customer perorangan merupakan ciri khas dari pada bisnis model yang menganut value-driven business models.

Untuk selanjutnya kesembilan elemen tersebut akan dipetakan ke dalam kanvas model bisnis (Business Model Canva), dengan cara ini model bisnis digambarkan dalam satu dokumen tunggal, mengenai bagaimana memahami, mengembangkan, menyelesaikan dan menilai model suatu bisnis usaha/industri yang dijalankan. 


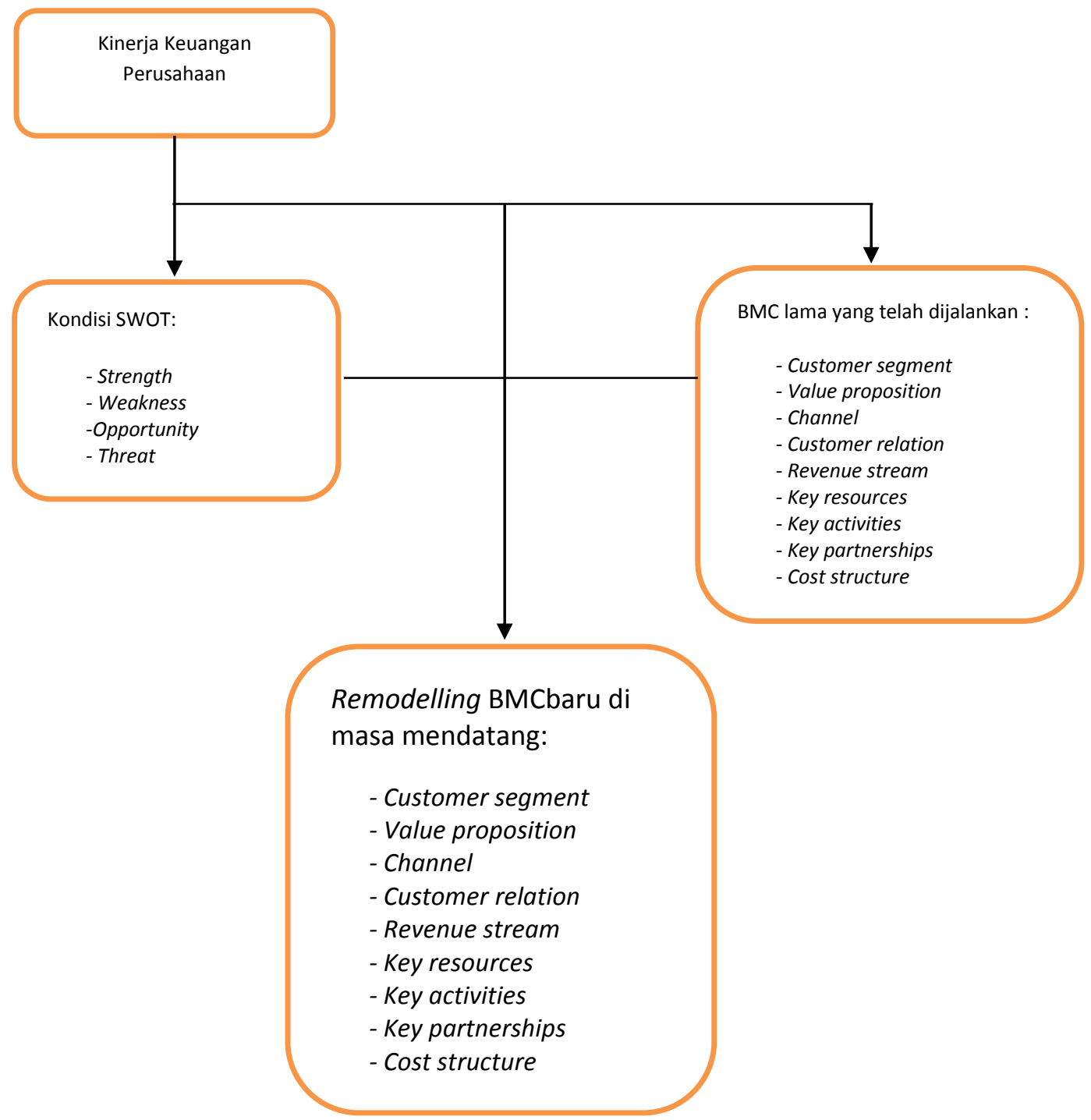

Gambar 6. Kerangka pemikiran

\section{METODE PENELITIAN}

Pendekatan penelitian yang digunakan dalam penelitian ini adalah pendekatan kualitatif. Dasar teori dalam pendekatan kualitatif adalah peneliti berusaha memahami suatu kondisi dan kaitannya dengan menganalisa dokumen tertentu. Berdasarkan permasalahan yang diajukan pada identifikasi serta rumusan masalah dalam penelitian, maka lebih mengutamakan pada masalah proses, makna, pemahaman, kompleksitas, interaksi, serta persepsi. Denzin dan Lincoln (di dalam Moleong, 2005:5) menyatakan bahwa penelitian kualitatif merupakan penelitian yang menggunakan latar alamiah dengan maksud menafsirkan fenomena yang terjadi dan dilakukan dengan jalan melibatkan berbagai metode yang ada. 
Penelitian ini termasuk dalam penelitian kualitatif deskriptif karena bermaksud untuk mendeskripsikan keterangan-keterangan tentang data yang di dapat dari lapangan berupa data tertulis ataupun lisan (wawancara) serta angket penilaian dari responden saat pelaksanaan penelitian.

\section{Teknik dan Prosedur Pengumpulan Data}

Data dari dokumen laporan dalam bentuk hard copy maupun soft copy yang ada di PT Sasakura Indonesia sekaligus sebagai subjek perusahaan yang di teliti. Jenis data primer yaitu data yang berasal langsung dari sumber data yang dikumpulkan secara khusus dan berhubungan langsung dengan permasalahan yang di teliti dengan cara observasi, wawancara, Sedangkan jenis data sekunder diperoleh melalui kajian pustaka, review penelitian relevan sebelumnya, dokumen-dokumen dan juga laporan rutin perusahaan.

\section{Metode Analisis Data}

Teknik analisis yang digunakan adalah analisis deskriptif yang memberikan gambaran dengan jelas dan benar. Teknis yang digunakan ialah analisis deskriptif yang memberikan gambaran dan makna dari indikator yang ada, membandingkan dan menghubungkan antara indikator yang satu dengan indikator lain.

\section{Analisa EFAS dan IFAS}

a) Faktor Eksternal (EFAS)

Faktor internal merupakan faktor-faktor yang mempengaruhi perusahaan yang berasal dari eksternal perusahaan. Dalam metode ini di sebut dengan EFAS (External Strategic Factor Summary). Peneliti akan menampilkan faktor-faktor yang termasuk dalam EFAS yang nantinya akan dimasukan dalam kategori Opportunity dan Threats dengan mengunakan rating tertentu, sesuai kaidah yang biasa digunakan dalam melakukan analisa EFAS.

b) Faktor Internal (IFAS)

Dalam metode ini di sebut dengan IFAS (Internal Strategic Factor Summary), dan peneliti akan menampilkan faktor-faktor yang termasuk dalam IFAS yang nantinya akan dimasukan dalam unsur-unsur yang berkategori Strength dan Weakness, dengan rating yang sudah ditentukan. Adapun bobot penilaian dapat mengunakan rating tertentu sesuai kaidah yang dipakai dalam analisa IFAS. 


\section{Pembuatan Business Model Canvas (BMC) yang baru}

Setelah dilakukan review SWOT, peneliti akan merancang faktor-faktor elemen dari BMC yang sudah ditentukan dan nantinya akan menjadi usulan kepada model bisnis yang baru bagi perusahaan. Diharapkan nantinya peusahaan dapat menerapkan business model canvas yang diusulkan ini.

\section{HASIL DAN PEMBAHASAN}

Penelitian ini perlu melakukan pendekatan dengan cara mendeskripsik hasil penelitian merupakan uraian dari seluruh data dan pembahasan yang pada akhirnya merupakan hasil penelitian. Pembahasan dengan menganalisis lingkungan eksternal dan internal untuk mengetahui kekuatan dan kelemahan serta peluang dan ancaman yang dihadapi saat ini, sehingga dapat menentukan alternatif-alternatif dari strategi-strategi yang muncul, kemudian dipilih dengam kombnasi yang paling besar untuk diterapkan di perusahaan, yang diuraikan pada bagian berikut:

\section{Analisis Industri}

Pemerintah berupaya mendorong agar industri desalinasi agar tetap berkembang. Industri ini dapat mendukung terhadap pencapaian target komitmen pembangunan proyek energi yang telah ditetapkan. Karena Pemerintah tetap bertekad optimis dapat mencapai target tersebut, dengan konsisten mencanangkan pembangunan proyek energi sebear 10000 MW di Indonesia. Yang mana proyek-proyek ini juga membutuhkan teknologi penunjang seperti industri desalinasi dengan jenis produk fresh water generation, Multi- stage flash, dan reheat type. Strategi bisnis PT Sasakura Indonesia dalam industri desalinasi ini juga mengunakan pertimbangan analisa Porter (Porter's Five Forces Analysis) yang meliputi analisis tingkat kompetisi antar kompetitor, tingkat ancaman pendatang baru, tingkat ancaman produk substitusi, tingkat posisi tawar pembeli, tingkat posisi tawar pemasok dalam bisnis produk dan jasa pada industri desalinasi.

\section{Business Model PT Sasakura Indonesia lama yang sedang dijalankan}

Business model menjelaskan latar belakang bagaimana suatu organisasi menciptakan, menyampaikan dan memperoleh nilai-nilai dari suatu bisnis. Konsep dari suatu bisnis model harus dapat dipahami oleh semua pihak yang terlibat dengan penyajian yang sederhana, relevan dan secara intuisi mudah dipahami dengan tidak 
bermaksud menyederhanakan fungsi dari pada organisasi perusahaan yang sangat kompleks.

Osterwalder dan Pigneur (2016), menginovasi dan membagi tahapan di dalam melakukan penyusunan suatu bisnis model ke dalam 9 elemen. Adapun business model canvas lama yang masih atau sedang dijalankan oleh perusahaan PT Sasakura Indonesia, elemen-elemen business model canvas tersebut telah diuraikan dan dapat dilihat pada tabel1.

Tabel 1. Business Model Canvas lama yang sedang dijalankan

\begin{tabular}{|c|c|c|c|c|c|}
\hline \multirow{3}{*}{\begin{tabular}{|l} 
Key Partnership \\
\\
\\
Government, \\
Project Owner and \\
Contraktor, Heavy \\
transport \\
equipment vendor, \\
Material handling \\
vendor, IT and \\
Equipment \\
production vendor, \\
Material/parts \\
vendor, Bank \\
support, Safety \\
and certification \\
vendor
\end{tabular}} & & \multirow{3}{*}{\multicolumn{2}{|c|}{$\begin{array}{l}\text { Value Propositions } \\
\\
\\
\\
\text { SDM yang handal, } \\
\text { Variasi peralatan, } \\
\text { perlengkapan } \\
\text { produksi, kualitas } \\
\text { produk dan } \\
\text { perlengkapan } \\
\text { berteknologi } \\
\text { tinggi, }\end{array}$}} & Customer Relationship & \multirow{3}{*}{$\begin{array}{l}\text { Business Group : } \\
\text { PT PLN, } \\
\text { PT Pertamina, } \\
\text { PT Bakrie Brothers, } \\
\text { PT Styromono } \\
\text { Indonesia, } \\
\text { PT Statomer, } \\
\text { PT Candra Asri } \\
\text { Petrochemical } \\
\text { Indonesia, } \\
\text { PT Mitsubishi } \\
\text { Chemical Indonesia, }\end{array}$} \\
\hline & $\begin{array}{l}\text { business } \\
\text { management, } \\
\text { marketing and } \\
\text { sales } \\
\text { management, } \\
\text { engineer, } \\
\text { technician, project } \\
\text { execution, } \\
\text { production } \\
\text { management. }\end{array}$ & & & $\begin{array}{l}\text { Assistance, dalam } \\
\text { bentuk interaksi } \\
\text { karyawan/tim } \\
\text { dengan pelanggan } \\
\text { yang dapat } \\
\text { dilakukan baik } \\
\text { selama } \\
\text { pemasaran, } \\
\text { produksi, } \\
\text { penawaran, } \\
\text { penjualan dan } \\
\text { maintenance, } \\
\text { serta purna jual, } \\
\text { Sasakura access } \\
\text { contact. }\end{array}$ & \\
\hline & $\begin{array}{l}\text { Kev Resources } \\
\text { Bahan baku, } \\
\text { Marketer, Engineer, } \\
\text { Technician, } \\
\text { Operator, Heavy } \\
\text { transport } \\
\text { equipment, } \\
\text { karyawan } \\
\text { outsourcing }\end{array}$ & & & $\begin{array}{l}\text { Channels } \\
\\
\text { Fixed sales, } \\
\text { Kemitraan BUMN, } \\
\text { tender proyek, } \\
\text { Sasakura website } \\
\text { access. }\end{array}$ & \\
\hline \multicolumn{3}{|c|}{$\begin{array}{l}\text { Cost Structure } \\
\text { Personnel Salary \& wages, Repair \& Maintenance, Equipment } \\
\text { Rental, Material Expenses, Insurance, Inspection, Camp } \\
\text { Safety Service, Electricity \& Water. }\end{array}$} & \multicolumn{3}{|c|}{$\begin{array}{l}\text { Revenue penjualan produk dan jasa temasuk jasa pelayanan } \\
\text { purna jual dan maintenance. }\end{array}$} \\
\hline
\end{tabular}

\section{Posisi perusahaan berdasarkan review SWOT PT Sasakura Indonesia}

\section{a. Analisis Lingkungan Eksternal (EFAS)}

Dalam kegiatan ini, peneliti melakukan kegiatan wawancara, dan juga sekaligus menyebarkan kuistioner yang berisi bberapa efaktor-faktor eksternal kepada responden dari manajemen PT Sasakura Indonesia melalui lembar kertas khusus untuk itu, dan responden menentukan faktor-faktor tersebut, dengan dikategorikan masuk ke dalam 
peluang atau ancaman, serta hasilnya buatkan menjadi nilai oleh peneliti. Kerahasiaan dari jawaban pendapat pribadi responden akan dijaga.

\section{b. Analisis Lingkungan Internal (IFAS)}

Peneliti menyebarkan kuistioner yang berisi indikator di internal PT Sasakura Indonesia, dan responden menentukan nilai indikator tersebut masuk kedalam kekuatan atau kelemahan yang hasilnya akan dirata-ratakan oleh peneliti.

Dari hasil pembobotan EFAS dan IFAS dapat diketahui bahwa Opportunity $=1,75$, Threats $=1,5$, Strength $=1,85$, dan Weakness $=1,23$. Urutan kombinasi alternatif strategi SWOT dari yang paling tinggi sampai yang terendah yaitu $\mathrm{SO}=3,6, \mathrm{ST}=3,35$, $\mathrm{WO}=2,98, \mathrm{WT}=2,75$. Dengan begitu maka prioritas kombinasi strategi memiliki nilai paling tinggi ialah strategi Strength+Oppotunity=3.6.

Tabel 2. Matriks Strategi

\begin{tabular}{|c|c|c|}
\hline $\begin{array}{l}\text { External Factors } \\
\text { (EFAS Table 4.3) }\end{array}$ & $\begin{array}{l}\text { Strengths (S) } \\
\text { S1. Kemitraan investasi asal Jepang } \\
\text { S2. Kualitas produk, Pelayanan, } \\
\text { dan Kepuasan pelanggan } \\
\text { S3. Self Financing dan Rasio } \\
\text { Finansial sebagai strategi keuangan } \\
\text { S4. Kemampuan SDM } \\
\text { S5. Penerapan Risk Management, } \\
\text { Safety culture dalam organisasi }\end{array}$ & $\begin{array}{l}\quad \text { Weakness (W) } \\
\text { W1. Persaingan di pasar } \\
\text { W2. Operational cost, dan } \\
\text { kemampuan bersaing harga } \\
\text { W3. Aksesibilitas ke } \\
\text { BUMN/BUMD dan lobby ke } \\
\text { Pemerintah } \\
\text { W4. Maintenance, fasilitas } \\
\text { lingkungan kerja } \\
\text { W5. Proses pengadaan barang } \\
\text { W6. Kurangnya biaya } \\
\text { marketing support } \\
\text { W7. Diversifikasi unit bisnis }\end{array}$ \\
\hline $\begin{array}{l}\text { Opportunities (O) } \\
\text { O1. Pertumbuhan order PT PLN } \\
\text { O2. Pertumbuhan order PT Pertamina } \\
\text { dan SKK Migas } \\
\text { O3. Pembangunan proyek energi }\end{array}$ & $\begin{array}{l}\text { SO Strategies } \\
\text { - Meningkatkan akses dan } \\
\text { kemitraan dengan BUMN, BUMD, } \\
\text { dan afiliasi dengan perusahaan } \\
\text { global Asia }\end{array}$ & $\begin{array}{l}\text { WO Strategies } \\
\text { - Memahami ceruk pasar untuk } \\
\text { memasuki pasar baru di energi } \\
\text { terbarukan } \\
\text { - Membangun strategi bersaing }\end{array}$ \\
\hline
\end{tabular}




\begin{tabular}{|c|c|c|}
\hline $\begin{array}{l}\text { terbarukan } \\
\text { O4. Persyaratan produk dan teknologi } \\
\text { yang handal } \\
\text { O5. Afiliasi dengan investor baru dari } \\
\text { Jepang atau Asia }\end{array}$ & $\begin{array}{l}\text { - Meningkatkan kualitas, } \\
\text { standard, dan pelayanan } \\
\text { - Menambah kekauatan financial } \\
\text { support }\end{array}$ & $\begin{array}{l}\text { yang fleksibel dan handal serta } \\
\text { memulai penetrasi pasar } \\
\text { - Meningkatkan efisiensi biaya } \\
\text { produksi, kemampuan bersaing } \\
\text { harga, dan menambah } \\
\text { marketing serta kemitraan }\end{array}$ \\
\hline $\begin{array}{l}\text { Threats } \\
\text { T1. Harga di masa mendatang } \\
\text { T2. Masuknya produk/jasa dari China } \\
\text { dan Korea } \\
\text { T3. Political and Regulation issue } \\
\text { T4. Tingkat fluktuasi biaya produksi, dan } \\
\text { dan inflasi mata uang } \\
\text { T5. Konglomerasi group investor dari } \\
\text { China } \\
\text { T6. Sistem manajemen mutu (ISO) dan } \\
\text { Prestasi dan sertifikat internasional } \\
\text { T7. Prestasi dan sertifikat internasional }\end{array}$ & $\begin{array}{l}\text { ST Strategies } \\
\text { - Menciptakan daya saing harga } \\
\text { produk, global partnership, dan } \\
\text { meraih ISO } \\
\text { - Mengantisipasi efek negatif } \\
\text { gejolak mata uang dengan cara } \\
\text { hedging } \\
\text { - Selalu mengantisipasi perubahan } \\
\text { dinamika politik, ekonomi, dan } \\
\text { sosial }\end{array}$ & $\begin{array}{l}\text { WT Strategies } \\
\text { - Menentukan harga yang wajar } \\
\text { dengan menurunkan profit } \\
\text { tanpa mengurangi kualitas } \\
\text { - Menurunkan biaya produksi } \\
\text { dan maitenance, agar dapat } \\
\text { dialokasikan ke biaya akses, } \\
\text { proses, marketing, dan rencana } \\
\text { diversifikasi produk masa depan } \\
\text { - Memantau perubahan } \\
\text { regulasi, dan sistem ISO }\end{array}$ \\
\hline
\end{tabular}

Dari tabel 2 dapat diketahui bahwa peruahaan akan pilihan mengambil strategi S+O. Kondisi strategi perusahaan dapat diterjemahkan sebagai strategi menggunakan kekuatan untuk meraih peluang yang ada dan berada di sel competitive advantages yang merupakan pertemuan dua elemen kekuatan dan peluang sehingga memberikan kemungkinan bagi suatu perusahaan untuk bisa berkembang lebih cepat dan melakukan ekspansi (growth oriented strategy).

\section{Membuat business model canvas baru yang sejalan dengan analisa SWOT yang baru pada PT Sasakura Indonesia yang sekarang}

Berdasarkan analisa yang telah dilakukan, perusahaan perlu menyesuaikan bisnisnya dalam bentuk business model canvas. Pelaksanaan strategi-strategi yang dapat digunakan harus mengacuh pada kombinasi strategi yang telah dijelaskan pada kombinasi strategi Strength + Oppurnity. Sehingga strategi ini dimasukkan ke dalam business model canvas yang baru. 
Desain kombinasi strategi Strength + Oppurnity, akan menjadi model strategi utama yang diambil oleh perusahaan untuk dilaksanakan di masa mendatang dalam menghadapi perubahan pasar dan kondisi bisnis perusahaan. Adapun remodelling business model canvas baru tersebut dijabarkan sebagai berikut:

Tabel 3. Business Model Canvas yang diusulkan

\begin{tabular}{|c|c|c|c|c|c|}
\hline \multirow{3}{*}{\begin{tabular}{|l} 
Key Partnership \\
\\
\\
-Meningkatkan \\
akses dan \\
kemitraan dengan \\
BUMN, BUMD, \\
-Afiliasi dengan \\
perusahaan global \\
Asia, \\
-Project Owner, \\
-Kontraktor, \\
-Material and \\
services vendors, \\
-Bank support, \\
-Safety and \\
certification \\
vendor.
\end{tabular}} & Key Activities & \multirow{3}{*}{\multicolumn{2}{|c|}{$\begin{array}{l}\text { Value Propositions } \\
\\
\\
\\
\\
\text {-Head office visit, } \\
\text {-Training centre, } \\
\text {-Trusty value, } \\
\text {-Quality, } \\
\text {-Custumers } \\
\text { satisfaction, } \\
\text {-Easy access, } \\
\text {-Perlengkapan } \\
\text { teknologi produksi } \\
\text { Multy Stage Flash } \\
\text {-Strong leader } \\
\text { untuk produk } \\
\text { desalinasi MSF } \\
\text { dan RH. }\end{array}$}} & Customer Relationship & \multirow{3}{*}{$\begin{array}{l}\text { Kelompok usaha: } \\
-P T \text { PLN, } \\
\text {-PT Pertamina, } \\
\text {-PT Bakrie Brothers, } \\
\text {-PT Styromono } \\
\text { Indonesia, } \\
\text {-PT Statomer, } \\
\text {-PT Candra Asri, } \\
\text {-Petrochemical } \\
\text { Indonesia, } \\
\text {-PT Mitsubishi } \\
\text { Chemical Indonesia, } \\
\text {-BUMN, dan BUMD } \\
\text { serta perusahaan, } \\
\text { Industrial/factory, } \\
\text { high building } \\
\text { construction and } \\
\text { equipment project, } \\
\text { dan infrastructure } \\
\text { project swasta } \\
\text { lainnya. }\end{array}$} \\
\hline & $\begin{array}{l}\text {-Marketing, } \\
\text {-Tender prospect } \\
\text { review, } \\
\text {-Project execution, } \\
\text {-Production, } \\
\text {-QC. }\end{array}$ & & & $\begin{array}{l}\text {-Factory visit in } \\
\text { Osaka after } \\
\text { project finishing, } \\
\text {-Assistance, } \\
\text {-Interaksi } \\
\text { karyawan/tim } \\
\text { dengan pelanggan } \\
\text { yang dapat } \\
\text { dilakukan baik } \\
\text { selama } \\
\text { pemasaran, } \\
\text { produksi, } \\
\text { penjualan dan } \\
\text { maintenance, } \\
\text { serta purna jual }\end{array}$ & \\
\hline & $\begin{array}{l}\text { Kev Resources } \\
\text {-Bahan baku, } \\
\text {-Skill Engineer, } \\
\text { Production assets } \\
\text { Material handling } \\
\text { equipment, } \\
\text {-Financial support }\end{array}$ & & & \begin{tabular}{|l} 
Channels \\
\\
-Fiixed sales, \\
-Kemitraan BUMN, \\
dan BUMD, \\
-Tender proyek, \\
-Regional agency, \\
-Sasakura website
\end{tabular} & \\
\hline \multicolumn{3}{|c|}{$\begin{array}{l}\text { Cost Structure } \\
\text { Personnel Salary \& wages, Repair \& Maintenance, Equipment } \\
\text { Rental, Material Expenses, Insurance, Inspection, Camp } \\
\text { Transport, Penalty, Work Environment \& Safety Service, } \\
\text { Electricity \& Water }\end{array}$} & \multicolumn{3}{|c|}{$\begin{array}{l}\text { Revenue penjualan produk dan jasa layanan lain temasuk jasa } \\
\text { pelayanan purna jual dan maintenance. }\end{array}$} \\
\hline
\end{tabular}

Dari business model canvas (BMC) yang diusulkan di atas, peneliti menawarkan beberapa point pada beberapa elemen BMC di mana point tersebut dapat dijadikan evaluasi terhadap PT Sasakura Indonesia untuk pengembangan business model yang sudah ada dengan pertimbangan sebagai berikut :

a) Pada Customer Segments, peneliti menambahkan project BUMN, BUMD, Industrial/factory, high building construction and equipment project, dan infrastructure, di mana projek seperti ini sedang tumbuh dengan cepat sejalan dengan otonomi daerah.

b) Pada Value Proposition, peneliti membuatnya menjadi SDM yang handal (berpengalaman dan bersertifikat), meningkatkan kualitas produk (quality), 
standard pelayanan yang memuaskan pelanggan (customer satisfaction), dan mempermudah akses komunikasi, head office visit, training centre, trusty value, dan juga memperbaiki perlengkapan produksi, fokus dan strong leader untuk produk Multi-flash flash dan reheat type. Kualitas SDM untuk tim pekerja juga diharapkan mampu meminimalisir accident yang menyebabkan kerugian yakni ganti barang, denda downtime, bahkan tidak dibayar.

c) Pada Channels, peneliti menambahkan untuk perlunya bagi perusahaan PT Sasakura Indonesia untuk kemitraan dengan BUMN/BUMD, tender proyek, Regional agency yang terbuka kemitraan bagi perusahaan swasta di daerah dan memperbaiki sistem komunikasi pada Sasakura website.

d) Pada Customer Relation, membuatkan untuk strategi factory visit in Osaka, Japan, after project finishing, Assistance. Selain itu itu melaksanakan interaksi karyawan/tim dengan pelanggan yang dapat dilakukan baik selama pemasaran, produksi, penjualan dan maintenance, serta purna jual.

e) Pada Revenue Streams, peneliti menambahkan atau lebih tepatnya mempertegas kembali untuk pengembangan bisnis PT Sasakura Indonesia tahun 2019-2024 yaitu mengembangkan unit usaha pada produk-produk lain, yang dapat akan menjadi target pendapatan bagi pengembangan usaha dari PT Sasakura Indonesia tahun 2019-2024 mendatang.

f) Pada Key Resources, peneliti menambahkan akan pentingnya memilih sumber bahan baku yang ideal sesuai spesifikasi, marketing support lebih agresif lagi dan terus menggalang kekuatan financial support.

g) Pada Key Activities, peneliti membuat tambahan untuk strategi utama dan penting yaitu teraktifitas marketing, tender prospect review, project execution, production, serta pentingnya pengawasan Quality Control (QC).

h) Pada Key Partnership, peneliti menambahkan upaya untuk meningkatkan akses dan kemitraan dengan BUMN, BUMD, dan memperluas afiliasi dengan perusahaan global Asia.

i) Pada Key Partners, peneliti membuatkan strategi meningkatkan akses dan kemitraan dengan BUMN, BUMD, afiliasi dengan perusahaan global asia, 
project owner, contraktor, subcontractor, material and services vendors, bank support, safety and spesial certification vendor.

j) Pada Cost Structure, peneliti memasukkan strategi personnel salary and wages, repair and maintenance, equipment, transport, penalty, work environment and safety service.

Tabel 4. Perbandingan BMC lama yang sedang dijalankan dengan BMC baru yang disusulkan

\begin{tabular}{|c|c|c|}
\hline Elemen & $\begin{array}{c}\text { BMC lama yang sedang } \\
\text { dijalankan }\end{array}$ & BMC baru yang disusulkan \\
\hline Customer Segments & $\begin{array}{l}\text { Kelompok usaha : } \\
\text { PT PLN, } \\
\text { PT Pertamina, } \\
\text { PT Bakrie Brothers, } \\
\text { PT Styromono Indonesia, } \\
\text { PT Statomer, } \\
\text { PT Candra Asri Petrochemical } \\
\text { Indonesia, } \\
\text { PT Mitsubishi Chemical Indonesia. }\end{array}$ & $\begin{array}{l}\text { Kelompok usaha: } \\
\text {-PT PLN, } \\
\text {-PT Pertamina, } \\
\text {-PT Bakrie Brothers, } \\
\text {-PT Styromono Indonesia, } \\
\text {-PT Statomer, } \\
\text {-PT Candra Asri Petrochemical } \\
\text { Indonesia, } \\
\text {-PT Mitsubishi Chemical Indonesia, } \\
\text {-BUMN, BUMD Industrialffactory, } \\
\text { high building construction equipment } \\
\text { project, dan infrastructure project } \\
\text { swasta lainnya. }\end{array}$ \\
\hline Value Proposition & $\begin{array}{l}\text { SDM yang handal, Variasi peralatan, } \\
\text { perlengkapan produksi, kualitas } \\
\text { produk dan perlengkapan berteknologi } \\
\text { tinggi, }\end{array}$ & $\begin{array}{l}\text {-Head office visit, } \\
\text {-Training centre, } \\
\text {-Trusty value, } \\
\text {-Quality, } \\
\text {-Operasi customers satisfaction, } \\
\text {-Easy access, } \\
\text {-Perlengkapan teknologi produksi } \\
\text { Multi- Stage Flash } \\
\text {-Strong leader untuk produk } \\
\text { desalinasi MSF dan RH. }\end{array}$ \\
\hline Channels & $\begin{array}{l}\text { Kemitraan BUMN, tender proyek, } \\
\text { Sasakura website acces. }\end{array}$ & $\begin{array}{l}\text {-Kemitraan BUMN, dan BUMD, } \\
\text {-Tender proyek, } \\
\text { - Subcontractor } \\
\text {-Regional agency, } \\
\text {-Sasakura website. }\end{array}$ \\
\hline Customer Relation & $\begin{array}{l}\text { Assistance, dalam bentuk interaksi } \\
\text { karyawan/tim dengan pelanggan yang } \\
\text { dapat dilakukan baik selama } \\
\text { pemasaran, produksi, pnawaran, } \\
\text { penjualan dan maintenance, serta }\end{array}$ & $\begin{array}{l}\text {-Factory visit in Osaka after project } \\
\text { finishing, } \\
\text {-Assistance, } \\
\text {-Interaksi karyawan/tim dengan } \\
\text { pelanggan yang dapat dilakukan baik } \\
\text { selama pemasaran, produksi, }\end{array}$ \\
\hline
\end{tabular}




\begin{tabular}{|c|c|c|}
\hline & purna jual, Sasakura access contact. & $\begin{array}{l}\text { penjualan dan maintenance, serta } \\
\text { purna jual. }\end{array}$ \\
\hline Revenue Streams & $\begin{array}{l}\text { Revenue penjualan produk dan jasa } \\
\text { temasuk jasa pelayanan purna jual dan } \\
\text { maintenance. }\end{array}$ & $\begin{array}{l}\text { Revenue penjualan produk dan jasa } \\
\text { layanan lain temasuk jasa pelayanan } \\
\text { purna jual dan maintenance. }\end{array}$ \\
\hline Key Resources & $\begin{array}{l}\text { Sumber bahan baku, Marketer, } \\
\text { Engineer, Technician, Operator, } \\
\text { Heavy transport equipment, karyawan } \\
\text { outsourcing }\end{array}$ & $\begin{array}{l}\text {-Sumber bahan baku, } \\
\text {-Skill Engineer, } \\
\text {-Production assets Material handling } \\
\text { equipment, } \\
\text {-Financial support. }\end{array}$ \\
\hline Key Activities & $\begin{array}{l}\text { marketing and sales management, } \\
\text { engineer, technician, project } \\
\text { execution, production management. }\end{array}$ & $\begin{array}{l}\text {-Marketing, } \\
\text {-Tender prospect review, } \\
\text {-Project execution, } \\
\text {-Production, } \\
\text {-QC. }\end{array}$ \\
\hline Key Partnership & $\begin{array}{l}\text { Pemerintah, Project Owner and } \\
\text { Contraktor, Heavy transport } \\
\text { equipment vendor, Material handling } \\
\text { vendor, IT and Equipment production } \\
\text { vendor, Material/parts vendor, Bank } \\
\text { support, Safety and certification } \\
\text { vendor }\end{array}$ & $\begin{array}{l}\text {-Akses dan kemitraan dengan BUMN, } \\
\text { BUMD, } \\
\text {-Afiliasi dengan perusahaan global } \\
\text { Asia, } \\
\text {-Project Owner, } \\
\text {-Contraktor dan Subcontraktor, } \\
\text {-Material and services vendors, } \\
\text {-Bank support, } \\
\text {-Safety and certification vendor. }\end{array}$ \\
\hline Cost Structure & $\begin{array}{l}\text { Personnel Salary \& wages, Repair \& } \\
\text { Maintenance, Equipment, Safety } \\
\text { Service, Electricity \& Water }\end{array}$ & $\begin{array}{l}\text { Personnel Salary \& wages, Repair \& } \\
\text { Maintenance, Equipment, Transport, } \\
\text { Penalty, Work Environment \& Safety } \\
\text { Service. }\end{array}$ \\
\hline
\end{tabular}

\section{KESIMPULAN DAN SARAN}

\section{Kesimpulan}

Dari hasil penelitian dan analisa yang telah dilakukan dapat disimpulkan, maka remodeling bisnis PT Sasakura Indonesia dengan menggunakan business model canvas (BMC) ini memberikan kesimpulan bahwa:

1. Business model PT Sasakura Indonesia yang sedang dijalankan perlu diperbaharui agar dapat beradaptasi dengan perubahan kondisi pasar baru dan meningkatkan keunggulan daya saing.

2. Posisi perusahaan berdasarkan review SWOT PT Sasakura Indonesia menunjukkan bahwa perusahaan PT Sasakura Indonesia masih memiliki peluang cukup baik untuk merebut pasar atau konsumen, dimana strategi yang dapat digunakan yaitu kombinasi strategi Strength-Opportunity. 
3. Berdasarkan analisa faktor eksternal dan internal, review SWOT dan model bisnis yang telah dijalankan sebelumnya, maka dapat dibuatkan remodelling business model canvas baru untuk mendukung dan strategi baru perusahaan dalam menjalankan dan pengembangan bisnis.

\section{Saran}

Berdasarkan pada hasil penelitian yang telah dilakukan, dengan mempertimbangkan pula kondisi keterbatasan yang ada, biaya yang tersedia, dan kendala masa waktu, maka penelitian ini masih perlu dilakukan penyempurnaan. Sebagai saran dari peneliti yaitu:

1. Hendaknya perusahaan mampu semaksimal mungkin untuk mengunakan keunggulan bersaing terutama quality, customers satisfaction, dan customers trust value pada produk desalinasi Multi-Stage Flash dan Reheat Type.

2. Dengan remodelling business model canvas yang baru ini maka implikasinya diharapkan perusahaan dapat melaksanakan strategi yang sudah dirancang untuk meraih prospek pasar baru pada industri terkait seperti peluang baru pada industri energi terbarukan, PLTGU, petrochemical, manufacture, dan seawater factory.

3. Untuk penelitian selanjutnya, dapat memperluas periode waktu objek masalah yang diteliti, dan menambah literatur sebagai perbandingan.

\section{DAFTAR PUSTAKA}

Burhan. B. (2001). Metodologi Penelitian Kualitatif. (Jakarta: Raja Grafindo Perkasa).

Casadesus, R.M. (2011). How to Design a Winning Business Model, (HBR: JanuaryFebruary 2011).

Christensen CM. (2001). The past and future of competitive advantage. MIT Sloan Management Review, 42:105-109.

David, F.R. (2006). Manajemen Strategis. Edisi Sepuluh, Hal.8. (Jakarta: Penerbit: Salemba Empat).

Duce, D., \& Giorgetti, C.S. (1998). Reference Models for Distributed Cooperative Visualization, Computer Graphics Forum, 17:4.

Fred, R.D. (2002). Manajemen Strategis. (Penerbit Konsep: Jakarta).

Geissdoerfer et al. (2017). The Cambridge Business Model Innovation Process, University of Cambridge, Cambridge, United Kingdom. 
Hadari, N. (1994), Metode Penelitian Ilmiah. (Jakarta: Rineka Cipta)

Halley, R.A.P. (2015). Pengembangan Model Bisnis PT.Cipta Wisata Mandiri. Fakultas Ekonomi, Magister Manajemen Universitas Gadjah Mada.

Hamed, O. A. (2005). "Overview of hybrid desalination systems-current status and future prospects", Desalination 186:207. doi: 10.1016 / j.desal. 2005.03.095, Retrieved June 21, 2018.

Heyes, Graeme et al. (2017). Developing and implementing circular economy business models in service-oriented technology companies, USA.

Hunger, J.David \& Thomas L. Wheelen. (2003). Manajemen Strategis. (Yogyakarta: ANDI Yogyakarta).

Husseini, M., \& Hutabarat J. (2006). Perencanaan Stratejik. (Jakarta: Gramedia).

Indriati, Putri.W., (2010). Analisis efisiensi desalinasi unit 1B PT Pembangkit JawaBali UP. Muara Karang, Fakultas Sains dan Teknologi, Universitas Islam Syarif Hidayatullah, Jakarta, 2010.

Jogiyanto, 2005. Sistem Informasi Strategik untuk Keunggulan Kompetitif, Hal.46. (Yogyakarta: Andi Offset).

Kotler, P., and Keller, K.L. (2011). Marketing management (13th ed), New Jersey:Pearson Education Limited.

Mahardhika, M.G..( 2015). Analysis of Customer Satisfaction and Business Model Canvass Implementation in Start-Up Business The Case of Eureka Interview. Fakultas Ekonomi, Magister Manajemen Universitas Gadjah Mada.

Marlienna, Sabrina. (2013). Developing New Business Model of Prima Family Health Club. Fakultas Ekonomi, Magister Manajemen Universitas Gadjah Mada.

Melina, S.W. (2015). Evaluasi Model Bisnis Pada Perusahaan X Menggunakan Business Model Canvas. Universitas Kristen Petra, Surabaya.

Mintzberg. H.Quin., \& James Brian. (1996). The Strategic Process, Concept, Contexts, Cases, Third Edition. (New Jersey, Prentice Hall International).

Misra, B. M., and Kupitz, J. (2004). "The role of nuclear desalination in meeting the potable water needs in water scarce areas in the next decades". Desalination. 166: 1. doi:10.1016/j.desal.2004.06.053, Retrieved June 21, 2018.

Moleong, L.J. (2005). Metodologi Penelitian Kualitatif. (Bandung: Remaja Rosdakarya).

Mullin, J.W., \& Walker (2010), Marketing management: A Strategic decision making approach (7th ed). (New York: Mc Graw Hill).

Nastiti, F., Ely. (2014). Analisis Portfolio Aplikasi dengan Business Model Canvas pada Produsen Air Minum Dalam Kemasan "UTRA" PT.Guwatirta Sejahtera. S2 Teknik Elektro, Universitas Gadjah Mada. 
Orellano et al. (2017). Business Model configuration for PSS: An explorative study, École Nationale Supérieure des Mines de Saint Etienne. France.

Osterwalder, A. et.al., (2010). Business Model Generation, (USA: John Wiley \& Sons, Inc.).

Owolabi, Adekola. (2016). The Business Model Canvas as a tool for building relevant business models for Engineering Firms, Centre for Entrepreneurial Research and Development, Nigeria.

Porter, E.M. (1993). Competitive Advangases. (Jakarta: Karisma Publishing).

Rangkuti, F. (2006), Analisis SWOT Teknik Membedah Kasus Bisnis. (Jakarta: Gramedia Pustaka Utama).

Sarwono, J. (2006). Metode Penelitian Kuantitatif dan Kualitatif. (Yogyakarta: Graha Ilmu).

Souza et al. (2018). Designing viable multi-commodity energy business ecosystems: corroborating the business model design framework for viability, USA.

Toro-Jarrí et al. (2016). Methodology for the of building process integration of business model Canvas and technological roadmap, Center for Quality and Manufacturing, Tecnologico de Monterrey, Mexico.

Usama, A.K.H. (2015). Perencanaan Bisnis Parkir Susun di Jakarta. Fakultas Ekonomi, Magister Manajemen Universitas Gadjah Mada.

Wicaksono, A. Arief et.al. (2017). Business Model in Electricity Industry Using Business Model Canvas Approach; The Case of PT Bukaka Teknik Utama Tbk, Bogor. 